\title{
Use of Color Metallographic Techniques to Study Welds
}

\author{
G. F. Vander Voort
}

Buehler Ltd., 41 Waukegan Road, Lake Bluff, IL 60044

Welding is a very important joining process and has been used extensively for at least the past 60 years. Like most processes, there is a need to control the process and insure a high quality end result. Welds are no exception and over the years there have been many spectacular failures of welded structures that emphasize this need. Many procedures involving non-destructive and destructive tests are used to study weldments. Metallographic examination can be performed by grinding a spot on the surface of a weld, its heat affected zones or nearby base metal (the metal being joined that was unaffected by the heat of the welding process). This is a reasonably nondestructive evaluation. However, destructive examination, where is specimen is removed from either the welded assembly or test coupons, is quite commonly preformed. Test coupons are often used to qualify the welder and ensure that the techniques and materials chosen will produce a weld with acceptable soundness and mechanical properties. Post mortems of failed weldments are also examined metallographically using sections removed from the welded assembly, generally after non-destructive examinations are completed.

In some cases, the welded structure is large and, in the case of a field failure, a section must be removed by flame cutting. This process produces a substantial damaged zone adjacent to the cut, perhaps as large as $10-15 \mathrm{~mm}$. When the section gets to the laboratory, the damaged cut region must be removed by a less-damaging cutting method, such as band sawing or abrasive sectioning. Then, the metallographer will cut out coupons using a laboratory abrasive cut-off saw that introduces less damage than production manufacturing equipment. Weld samples often tend to be large and irregular in shape. Many will not fit within a standard 1-, 1.25-, 1.5- or 2-inch (25-, 30-, 40- or 50-mm) diameter mold for compression molding. In such cases, the metallographer often builds a mold using bent sheet metal, coated perhaps with a mold release agent, places the specimen inside this mold (after the mold is glued to a suitable base plate), and encapsulates the specimen with epoxy resin. After it has cured, the specimen can be ground and polished using a wide variety of semi-automated equipment.

The specimen is examined in the as-polished condition for voids of different types, such as porosity from gas evolution or shrinkage cavities, cracks that may be present in either the weld metal or the heat affected zone, regions where the weld did not exist (lack of fusion or lack of penetration) and for nonmetallic inclusions associated with the welding operation, chiefly slag-type in nature. Then, the metallographer will etch the specimen to study both the macrostructure and the microstructure using an etchant appropriate for the alloy. In some cases, the weld metal is of sufficiently different composition that an etchant chosen to etch the base metal and heat affected zone will not reveal the weld metal structure, and vice versa. If the specimen has been polished, the macrostructural details are usually adequately revealed by the etchant used to reveal the microstructure. In some studies, the metallographer will macroetch the specimen after grinding and study the macrostructure. This specimen is not suitable for microstructural examination. 
Most etchants used to reveal the structure of welds are standard general-purpose etchants. After examination with such an etch, it may prove to be valuable to use a color etching technique, as these can be far more sensitive for revealing grain structure, segregation and residual strain and deformation. However, these etchants are not widely used. Their use does require a very well prepared specimen for good results. But this level of perfection is easily achieved with modern equipment and consumable products. Figure 1 shows an example of the superiority of color etching over standard etchants in revealing the grain structure of a low-carbon steel weld.
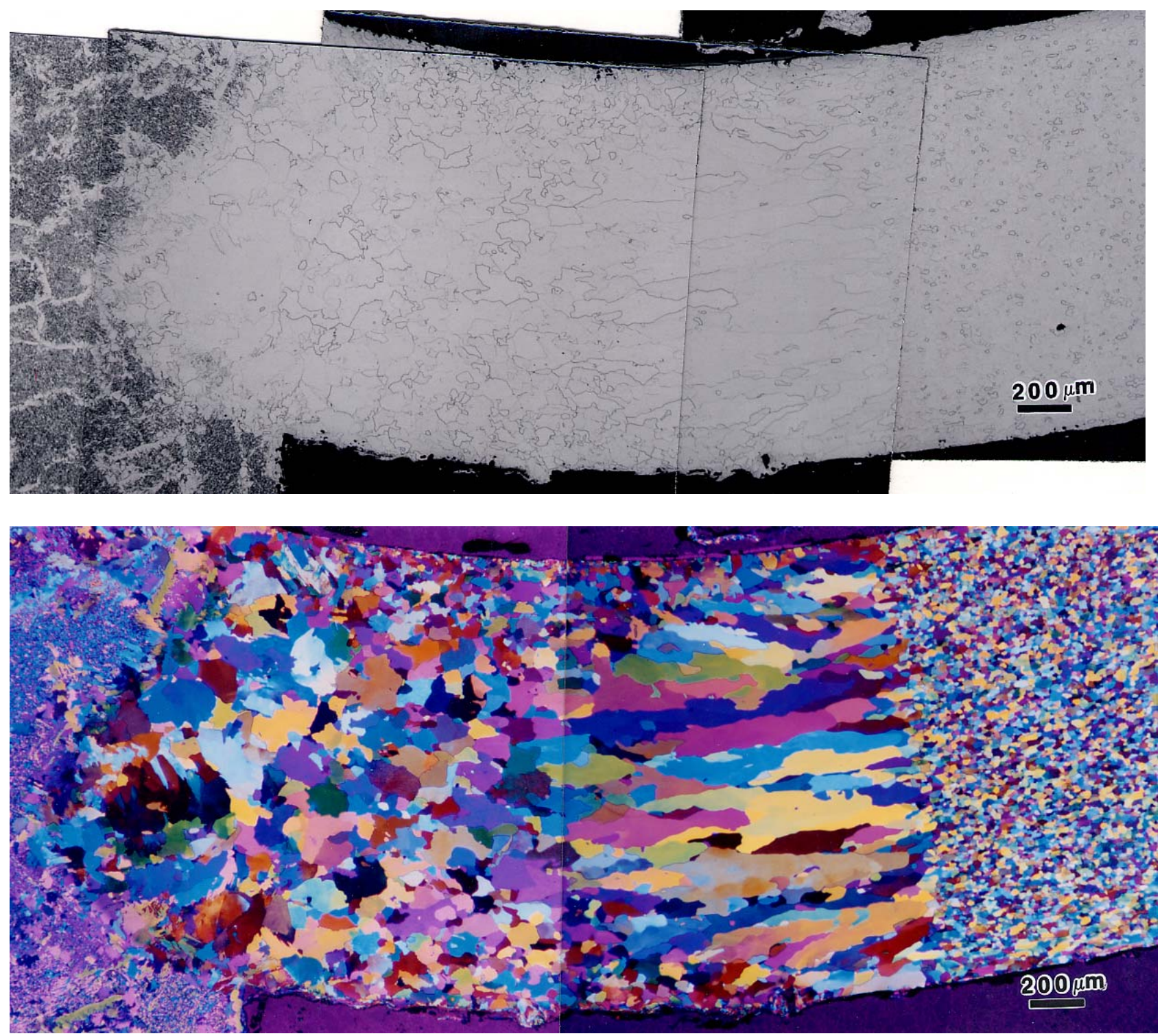

Figure 1. Example of a welded low-carbon steel etched with $2 \%$ nital (top) and Klemm's I (bottom) showing the clear superiority of color etching in revealing the grain structure. The as-cast weld metal is shown at the far left and the base metal is shown at the far right, above the $\mu \mathrm{m}$ bar. In between, we see the heat affected zone starting with coarse irregular grains adjacent to the fusion line, progressing to finer more uniformly shaped grains, then to columnar grains and finally to the very fine-grained equiaxed ferrite grains in the base metal. 